\title{
Awareness, Attitude, and Practice of Breast Cancer Screening Women, and the Associated Socio-Demographic Characteristics, in Northern Iran
}

\author{
Karimollah Hajian Tilaki ${ }^{1, *}$ and Sahar Auladi ${ }^{2}$ \\ ${ }_{2}^{1}$ Department of Biostatistics and Epidemiology, Babol University of Medical Sciences, Babol, IR Iran \\ ${ }^{2}$ Faculty of Medicine, Babol University of Medical Sciences, Babol, IR Iran \\ ${ }^{*}$ Corresponding author: Karimollah Hajian Tilaki, Department of Biostatistics and Epidemiology, Babol University of Medical Sciences, Babol, IR Iran. Tel: +98-1132190560, \\ E-mail:drhajian@yahoo.com \\ Received: July 6, 2015; Accepted: July 11, 2015
}

\begin{abstract}
Background: Breast cancer is the most common malignancy among women, with a high rate of mortality. The burden of disease and its serious outcome could be prevented by early detection.

Objectives: Thus, the objective of this study was investigation the awareness, attitude and practice of breast cancer screening women. Patients and Methods: This cross-sectional study has conducted on 500 representative samples of women aged 20 - 65 years who referred to urban area of Babol health centers in 2012. The data have collected with standard questionnaire. The demographic data, the knowledge of risk factors and symptoms and sign, the health belief, and the practice of women in breast cancer screening have collected by interview. Results: The results show that only $14.8 \%$ of participants had a high level of knowledge for breast cancer risk factors and $33.8 \%$ at high level of awareness of symptoms and signs. The level of awareness has significantly associated with higher age $(\mathrm{P}=0.03)$ and higher educational level $(\mathrm{P}=0.04)$. Only $10.2 \%$ and $8.4 \%$ of women have performed breast self- examination (BSE) monthly and breast clinical examination (BCE) annually respectively. The practice of women with BSE has significantly associated with aging $(\mathrm{P}=0.005)$, higher educational level ( $\mathrm{P}$ $=0.007)$, higher knowledge $(\mathrm{P}=0.001)$ and positive attitude toward perceived benefits and confidence and health motivation $(\mathrm{P}=0.001)$. Conclusions: The low level of awareness and practice of breast cancer screening have found in this study, emphasized an extension of framework health educational program, particularly in younger and low educated women.
\end{abstract}

Keywords: Awareness; Attitude; Practice; Breast Self- Examination; Breast Clinical Examination; Socio-Demographic Characteristics

\section{Background}

Breast cancer is the most common malignancy among women in the world. A worldwide report estimated $13,835,000$ cases and 458,400 deaths have attributed to the breast cancer in 2010, and then it has estimated $23 \%$ of total new cases of cancer and included $14 \%$ of total deaths due to the malignancy (1). In Islamic Republic of Iran, breast cancer has also included $24.4 \%$ of total malignancy and it was the highest malignancy incidence among the Iranian women with incidence rate of 36 per 100,000 women (2). In northern Iran, it was also a high incidence rate cancer among the women, estimated $21.4 \%$ of total diagnosed cancer (3). The increased incidence rate of breast cancer in recent decades in Iran has been due to changes in life style and fertility behaviors toward the western countries which were the most determinants of its increased risk (4). The primary susceptible risk factors are including genetic susceptibility, family history, confirmed hyperplasia, long duration of menarche (starting early age and terminating older age), postmenopausal obesity, oral contraceptive, postmenopausal hormone therapy, late first pregnancy (30 years or older), lack of breastfeeding, smoking, alcohol consumption, and lack of physical activities $(1,4)$.

Investigations have shown "breast cancer screening" programs for early diagnosis and early treatment have increased the survival rate and substantially prevent the recurrence and mortality $(5,6)$. Breast clinical examination (BSC), breast self- examination (BSE), and mammography for breast cancer screening (BCS) have important roles in early diagnosis. American cancer society recommended BCE for women aged 20 or older, and mammography for women aged 40 or older. However, the practices of women with respect to BCE and BSE or mammography have depended on their awareness, attitudes, socio- demographic characteristics and cultural issues. A study among Iranian health workers women has reported that despite $63 \%$ of women have been aware of how to use BCE, only $6 \%$ performed BCE monthly (7). Lack of positive attitudes and cultural barriers of women regarding BCS, has led breast cancer diagnosis almost in the late stages (3 or even 4) among the Iranian women that involved with total masterectomy and high rate of recurrence as well (2). Nevertheless, some evidences have shown an increased level of education among the Iranian women in this decade, the data regarding the awareness, attitude and practice of BCS has been scarce particularly in the north of Iran.

\section{Objectives}

Thus, this study has conducted to investigate the awareness, attitude, practice of BCS and the associated sociodemographic characteristics among the Iranian women.

\section{Patients and Methods}

This cross sectional study has conducted with representative samples of 500 women aged 20 - 65 years who have

Copyright (C) 2015, Iranian Journal of Cancer Prevention. This is an open-access article distributed under the terms of the Creative Commons Attribution-NonCommercial 4.0 International License (http://creativecommons.org/licenses/by-nc/4.0/) which permits copy and redistribute the material just in noncommercial usages, provided the original work is properly cited. 
referred to Babol urban health centers in 2012. A cluster sampling technique has used in sampling procedure. In the first step 10 clusters as defined by urban health centers have selected randomly. Then, within each health center, 50 women aged 20 to 65 years who have refereed to health center for receiving any health cares (e.g., vaccination for their child, or family planning, etc.) have selected consecutively. The data of knowledge of breast cancer, their belief and attitude and their practice have collected with a standard questionnaire by interview. The validity and reliability of different domains of this questionnaire have confirmed by several studies (8-10). In first part of the questionnaire, the demographic data including age, educational level of women and husbands, occupation, family history of breast cancer, history of pregnancy and duration of breastfeeding have collected. The main domains of questionnaire had three parts including knowledge regarding risk factors (14 items), knowledge of signs and symptoms (8 items), health belief in 6 domains (susceptibility, seriousness, benefits, barriers, confidence, health motivation ) and practice of BCE and BSE (3 items). The knowledge of each of 14 items of risk factors has scored as 0 or 1 for false and true answer respectively. These scores have summed; the possible range was from 0 to 14 and then they have categorized as 11 - 14 as high, 7 - 10 as moderate and $<7$ as low level of awareness. The knowledge of signs and symptoms has also scored as 0 or 1 for false and true answer of each item respectively and the possible sum of scores has ranged from 0 to 8. Finally, it has categorized in three level as high (score 5 - 8), moderate (score $4-5$ ) and poor (score $<4$ ). In the part of health belief, each item have scored using Likert scale 1 (absolutely disagree) to 5 (absolutely agree). In each domain, the mean score has calculated. If the average score was higher than the mid-point scale of item (as defined by 3 in Likert scale), it has categorized as positive attitude and $\leq 3$ as negative attitude but in the domain of barriers the direction of response has differed with others, the reversed have performed in its categorization. The overall positive attitude has defined as having 3 or more of 6 domains of health belief being as positive. The frequency of practice of BSE has responded with 5 choices (I do not know at all, I know but I never applied, I apply whenever it comes my mind, once in a month, others). The BCE and frequency of its performing have recorded with 5 choices (never, yes if have any complaint, once in a year, once in two years, others), and the knowledge of mammography and the frequency of its performing have recorded with 5 choices as well (I do not know, yes I know but I never underwent, once in a year, every two years, others). The internal consistency of different domains of questionnaire has assessed using Cronbach's alpha reliability coefficient. The reliability coefficient was higher than $80 \%$ in different domains. The study protocol was "to approach by the Ethical Research Council of Babol University of Medical Sciences", and then, "all participants have given a written consent prior participation" in the study.

In statistical analysis we have used SPSS software. The Chi-square test has used in analysis for categorical vari- ables. We have also performed logistic regression model to estimate the odds ratio of demographic characteristic and the knowledge of risk factors and symptoms and signs in the lack of performance in regular practice of women on BSE and BCE. In the logistic regression model, the response variable has defined as lack of regular practice of performing BSE as defined by not having once in a month and performing BCE as not once in a year. The 95\% confidence interval (CI) for OR have estimated and the Pvalue $<0.05$ have considered as significant level.

\section{Results}

The mean age $( \pm$ SD) of participants was $31.5 \pm 9.3$ years and the average of menarche age $( \pm$ SD) and the average age at 1st pregnancy were $13.2 \pm 1.4,21.7 \pm 3.9$ years respectively. The mean number of pregnancy was $1.6 \pm 1.4$ and the average duration of breastfeeding $26.3 \pm 27.8$ months; thirty six subjects (7.1\%) were post- menopausal with the average age of $46.9 \pm 5.02$ years. About $46.3 \%$ of women were housekeepers and $21 \%$ were teachers or health care workers or nurses. Roughly $71.2 \%$ of women have satisfied with their family income and 33 cases (6.6\%) had a family history of breast cancer but none of samples had history of breast cancer themselves. About 238 women (47.6\%) have declared that they had no information regarding to breast cancer and among those who have expressed they have some information, the source of information was health care workers (32.4\%), and magazine, books and brochure (32.4\%) were the most common source. With respect to each risk factor separately, $79.8 \%$ of women were aware of alcohol consumption as a risk factor and the family history (78.8\%), smoking (63.8\%), exposure to radiation (60.6\% ) increasing age (45.4\%) has informed as possible risk factors of breast cancer and 53.4\% of women have expressed breastfeeding as a determinant of decreasing breast cancer risk while less than $30 \%$ were aware of early menarche age, late age at first pregnancy and oral contraceptive as possible risk factors (Table 1). Overall, $52 \%$ of participants had low, 32.2\% moderate and $14.8 \%$ had high level of knowledge of breast cancer risk factors. The level of knowledge was significant higher in women aged 50 years or older as compared with $<50$ years $(\mathrm{P}=0.03)$. In addition, the level of awareness of risk factors have significantly associated with educational level of women $(\mathrm{P}=0.04)$ and women with education at university level had a higher level of awareness compared with low education. Regarding to awareness of sign and symptom of breast cancer, $32.4 \%$ were poor, $32.8 \%$ moderate and $33.8 \%$ had a high knowledge. The highest percentage of knowledge was the presence of breast mass (75.4\%) and enlargement of neighboring lymph nodes (56.6\%), abnormal enlargement of breast (54.4\%) and bloody discharge from nipple expressed as symptoms of breast cancer (51.8\%). The knowledge of other symptoms was almost less than 50\%. Additionally, a significant association between higher age and awareness of breast cancer symptoms and signs has been observed $(\mathrm{P}=0.001)$. Although higher education at university level has tended 
to increase the level of awareness of symptoms and sign but it was no statistically significant. Table 2 has shown the majority of women (94.8\%) had a poor conceived of susceptibility and confidence (74.2\%) as negative belief. Only $36 \%$ of women have perceived breast cancer as serious disease and $63.2 \%$ have believed the benefits of breast cancer screening and $94.8 \%$ have reported fewer barriers for BSE as a positive attitude and roughly half of subjects had a positive health motivation toward breast examination. A significant association has found between perceived susceptibility, seriousness, barriers and benefits of BSE with educational level but not for confidence. Table 3 has shown that $37.2 \%$ of subjects have no information about BSE at all and only $10.2 \%$ had regular practice as once in a month for BSE. As Tables 3 and 4 have shown, positive attitude and higher knowledge of risk factors have significantly corresponded with performing both BSE and BCE $(\mathrm{P}=0.001)$. Additionally, roughly $80 \%$ of women have not attended any educational program regarding BSE. A significant association has observed between age of women and educational level with regular practice of $\mathrm{BSE}(\mathrm{P}=0.005$ and $\mathrm{P}=0.007$, respectively) whereas a higher percentage of women aged 50 or older (17.2\%) have practiced BSE and the regular practice of BSE were significantly higher in women with education at university level $(\mathrm{P}=0.005)$. Regarding to $\mathrm{BCE}, 74.5 \%$ of participants have never attended to clinic for BCE at all and only $8.4 \%$ had a regular examination as once in a year. The higher knowledge of risk factors has significantly associated with regular BCE $(\mathrm{P}=0.001)$. In addition, $39.6 \%$ of participants have not known mammography at all and on overall only $12.1 \%$ samples had experience of mammography at least once in their life but among 108 women aged 40 or older, $28.5 \%$ have applied mammography at least one time. Performing mammography has significantly associated with awareness of risk factors and age but not with educational level. Table 5 has shown that increasing aged 30 or older the odds ratio of the lack of performance for
BSE has decreased significantly in comparison with aged $<30$ years $(\mathrm{P}=0.001)$. A higher educational level of women at university level $(\mathrm{OR}=0.31,95 \% \mathrm{CI}$ : 0.14, 0.69) and higher level of education of the husband $(\mathrm{OR}=0.41,95 \% \mathrm{CI}$ : 0.18 - 0.91) have inversely associated with lack of performance of BSE. Among married women as compared with singles $(\mathrm{OR}=0.31,95 \% \mathrm{CI}: 0.17,0.59)$ and women who worked outside of their houses as compared with housewives had

Table 1. The Frequency and Percentage Among the Women Regarding the Knowledge of Each Breast Cancer Risk Factor ${ }^{a}$

\begin{tabular}{lcc}
\hline Risk Factors & Present & Absent \\
\hline Increasing age & $227(45.4)$ & $273(54.6)$ \\
\hline Parity & $164(32.8)$ & $336(67.2)$ \\
\hline 1st pregnancy at age $\geq \mathbf{3 0}, \mathbf{y}$ & $147(29.4)$ & $353(70.6)$ \\
\hline Age of menopause $\geq \mathbf{5 0}, \mathbf{y}$ & $103(20.6)$ & $397(89.4)$ \\
\hline Menarche age $<\mathbf{1 1} \mathbf{y}$ & $113(22.6)$ & $387(77.4)$ \\
\hline Family history & $394(78.8)$ & $106(21.2)$ \\
\hline Obesity & $244(48.8)$ & $256(51.2)$ \\
\hline Oral contraceptive pills & $126(27.2)$ & $364(74.8)$ \\
\hline Breastfeeding & $267(53.4)$ & $233(46.6)$ \\
\hline Alcohol & $399(79.8)$ & $101(20.2)$ \\
\hline Smoking & $319(63.8)$ & $181(36.2)$ \\
\hline Exposure to radiation & $313(60.6)$ & $197(39.3)$ \\
\hline Benign mass & $218(42.6)$ & $282(56.4)$ \\
\hline Hormone therapy & $163(32.6)$ & $237(67.4)$ \\
\hline D Dar
\end{tabular}

${ }^{\mathrm{a}}$ Data are presented as No. $(\%)$

Table 2. The Distribution of "Different Domains of Belief" Respecting the Breast Cancer ${ }^{\mathrm{a}}$

\begin{tabular}{lccc}
\hline Beliefs & Positive Attitude & Negative Attitude & PValue \\
\hline Susceptibility & $26(5.2)$ & $471(94.8)$ & 0.001 \\
Seriousness & $182(36.8)$ & $312(63.2)$ & 0.001 \\
Barriers & $314(63.2)$ & $183(36.8)$ & 0.001 \\
Benefits & $471(94.8)$ & $26(5.2)$ & 0.001 \\
Confidence & $117(23.8)$ & $374(76.2)$ & 0.001 \\
Health motivation & $243(49.3)$ & $250(50.7)$ & 0.75 \\
\hline
\end{tabular}

a Data are presented as No. (\%).

Table 3. The Frequency and Percentage of Number of Breast Self- Examination and Breast Clinical Examination Practice Among the Women, Respecting the Level of Knowledge of Risk Factors ${ }^{\text {a }}$

\begin{tabular}{|c|c|c|c|c|c|}
\hline \multirow[t]{2}{*}{ Performance } & \multicolumn{4}{|c|}{ Knowledge } & \multirow{2}{*}{ PValue } \\
\hline & Low & Moderate & High & Total & \\
\hline Practice of BSE & & & & & 0.001 \\
\hline I do not know at all & $139(53.9)$ & $44(26.5)$ & $3(4.1)$ & $186(37.2)$ & \\
\hline I know how to do but I never did & $58(22.3)$ & $47(28.3)$ & $17(23.0)$ & $122(24.4)$ & \\
\hline Whatever I remember I do & $47(18.1)$ & $52(31.3)$ & $36(48.6)$ & $135(27.0)$ & \\
\hline I do once per month & $13(5.0)$ & $20(12.0)$ & $18(24.3)$ & $519(10.2)$ & \\
\hline Others & $3(1.2)$ & $3(1.8)$ & - & $6(1.2)$ & \\
\hline Total & $260(100)$ & $166(100)$ & $74(100)$ & $500(100)$ & \\
\hline Practice of BCE & & & & & 0.001 \\
\hline Never & $217(83.5)$ & $116(69.9)$ & $41(55.4)$ & $374(74.8)$ & \\
\hline If I complain a pain & $19(7.3)$ & $16(9.8)$ & $13(17.6)$ & $48(9.6)$ & \\
\hline Once per year & $12(4.6)$ & $19(11.4)$ & $12(16.2)$ & $43(8.6)$ & \\
\hline Every two years & $4(1.5)$ & $6(3.6)$ & $4(5.4)$ & $14(2.8)$ & \\
\hline Others & $8(3.1)$ & $9(5.4)$ & $4(5.4)$ & $21(4.2)$ & \\
\hline Total & $260(100)$ & $166(100)$ & $74(100)$ & $500(100)$ & \\
\hline
\end{tabular}

${ }^{\mathrm{a}}$ Data are presented as No. $(\%)$. 
significantly lower odds of lack of performance in BSE. In addition, higher level of knowledge of risk factors (OR = $0.12,95 \% \mathrm{CI}: 0.07,0.21)$ and symptoms/signs $(\mathrm{OR}=0.13,95 \%$ CI: 0.07-0.22) has been found that inversely associated with lack of BSE performance. Negative attitude has increased the odds of lack of performance in BSE as 2.53 times (95\%
CI:1.68,3.80). Also as Table 4 has shown women with age 30 or older, married women and those who had a high awareness of risk factors and symptom and sign have observed significantly lower odds of lack of performance in BCE as well and negative attitude increased the odds 3.3 times (95\%CI: 2.08 - 5.24) as compared with positive attitude.

Table 4. The Frequency and Percentage of Number of Breast Self-Examination and Breast Clinical Examination Practice Among the Women With Respect to Positive and Negative Attitude ${ }^{a}$

\begin{tabular}{|c|c|c|c|c|}
\hline \multirow[t]{2}{*}{ Performance } & \multicolumn{3}{|c|}{ Attitude } & \multirow[t]{2}{*}{ PValue } \\
\hline & Negative & Positive & Total & \\
\hline Practice of BSE & & & & 0.001 \\
\hline I do not know at all & $146(42.4)$ & $35(25.9)$ & $181(38.1)$ & \\
\hline I know how to do but I never did & $86(25.3)$ & $27(20.0)$ & $113(23.8)$ & \\
\hline Whatever I remember I do & $79(23.2)$ & $48(35.6)$ & $127(26.7)$ & \\
\hline I do once per month & $24(7.1)$ & $24(17.8)$ & $48(10.1)$ & \\
\hline Others & $5(1.5)$ & $1(0.7)$ & $6(1.3)$ & \\
\hline Total & $340(100)$ & $135(100)$ & $475(100)$ & \\
\hline Practice of BCE & & & & 0.001 \\
\hline Never & $267(78.5)$ & $87(64.4)$ & $354(74.5)$ & \\
\hline If I complain a pain & $30(8.8)$ & $17(12.6)$ & $47(9.9)$ & \\
\hline Once per year & $20(5.9)$ & $20(14.8)$ & $40(8.4)$ & \\
\hline Every two years & $9(2.6)$ & $4(3.0)$ & $13(2.7)$ & \\
\hline Others & $14(4.1)$ & $7(5.2)$ & $21(4.4)$ & \\
\hline Total & $34(100)$ & $135(100)$ & $475(100) \mathrm{b}$ & \\
\hline
\end{tabular}

Table 5. The Odds Ratio (OR) and Its 95\% Confidence Interval (CI) for the Lack of Performance of Breast Self-Examination and Breast Clinical Examination ${ }^{\mathrm{a}}$

\begin{tabular}{|c|c|c|c|c|}
\hline \multirow[t]{2}{*}{ Variables } & \multicolumn{2}{|c|}{ BSE } & \multicolumn{2}{|c|}{ BCE } \\
\hline & OR $(95 \% \mathrm{CI})$ & P Value & OR $(95 \% \mathrm{CI})$ & PValue \\
\hline \multicolumn{5}{|l|}{ Age group, $y$} \\
\hline$<30$ & $1(-)$ & - & $1(-)$ & \\
\hline $30-39$ & $0.31(0.20,0.47)$ & 0.001 & $0.34(0.20,0.58)$ & 0.001 \\
\hline $40-49$ & $0.38(0.22,0.64)$ & 0.001 & $0.30(0.16,0.54)$ & 0.001 \\
\hline$\geq 50$ & $0.37(0.17,0.82)$ & 0.001 & $0.56(0.21,0.16)$ & 0.24 \\
\hline \multicolumn{5}{|c|}{ Women's education level } \\
\hline Illiterate/primary & $1(-)$ & - & $1(-)$ & - \\
\hline Elementary & $0.54(0.21,1.39)$ & 0.20 & $0.86(0.32,2.32)$ & 0.76 \\
\hline High school & $0.33(0.14,0.78)$ & 0.01 & $0.82(0.34,1.96)$ & 0.64 \\
\hline University level & $0.31(0.14,0.69)$ & 0.005 & $0.84(0.37,1.91)$ & 0.68 \\
\hline \multicolumn{5}{|c|}{ Husband's education level } \\
\hline Illiterate/primary & $1(-)$ & & $1(-)$ & - \\
\hline Elementary & $0.98(0.37,2.69)$ & 0.97 & $0.33(0.10,1.11)$ & 0.07 \\
\hline High school & $0.45(0.19,1.03)$ & 0.06 & $0.39(0.13,1.21$ & 0.10 \\
\hline University level & $0.41^{`}(0.18,0.91)$ & 0.03 & $0.39(0.13,1.15)$ & 0.09 \\
\hline \multicolumn{5}{|c|}{ Occupation of women } \\
\hline Housewife & $1(-)$ & - & $1(-)$ & - \\
\hline Worker & $0.67(0.46,0.96)$ & 0.03 & $1.10(0.72,1.64)$ & 0.65 \\
\hline \multicolumn{5}{|l|}{ Marital status } \\
\hline Single & $1(-)$ & - & $1(-)$ & - \\
\hline Married & $0.31(0.17,0.59)$ & 0.001 & $0.14(0.04,0.45)$ & 0.001 \\
\hline \multicolumn{5}{|l|}{ Family income } \\
\hline Not sufficient & $1(-)$ & - & $1(-)$ & - \\
\hline Sufficient & $0.73(0.48,1.6)$ & 0.14 & $0.81(0.49,1.32)$ & 0.39 \\
\hline \multicolumn{5}{|l|}{ Information of $B C$} \\
\hline No & $1(-)$ & - & $1(-)$ & - \\
\hline Yes & $0.14(0.09,0.21)$ & 0.001 & $0.25(0.15,0.41)$ & 0.001 \\
\hline
\end{tabular}


Hajian Tilaki Ket al.

\begin{tabular}{|c|c|c|c|c|}
\hline \multicolumn{5}{|c|}{ Family history } \\
\hline No & $1(-)$ & - & $1(-)$ & - \\
\hline Yes & $0.79(0.37,1.67)$ & 0.54 & $0.64(0.24,1.72)$ & 0.38 \\
\hline \multicolumn{5}{|c|}{ knowledge of risk factors } \\
\hline Low & $1(-)$ & - & $1(-)$ & - \\
\hline Moderate & $0.39(0.26,0.59)$ & 0.001 & $0.40(0.24,0.66)$ & 0.001 \\
\hline High & $0.12(0.07,0.21)$ & 0.001 & $0.23(0.20,0.41)$ & 0.001 \\
\hline \multicolumn{5}{|c|}{ Knowledge of symptoms and signs } \\
\hline Low & $1(-)$ & - & $1(-)$ & - \\
\hline Moderate & $0.28(0.17,0.47)$ & 0.001 & $0.81(0.44,1.48)$ & 0.49 \\
\hline High & $0.13(0.07,0.22)$ & 0.001 & $0.33(0.19,0.57)$ & 0.001 \\
\hline \multicolumn{5}{|l|}{ Attitude } \\
\hline Positive & $1(-)$ & & $1(-)$ & \\
\hline Negative & $2.53(1.68,3.80)$ & 0.001 & $3.30(2.08,5.24)$ & 0.001 \\
\hline
\end{tabular}

\section{Discussion}

The findings show that $37.2 \%$ of participants have no information of BSE and only $10.1 \%$ of subject under study have performed BSC regularly as once per month. On overall, $39.6 \%$ of women have no knowledge of mammography not at all but $28.5 \%$ of women aged $>40$ years had at least one mammography. Also only $8.4 \%$ of samples had BCE regularly as once per year. Our results also have demonstrated and have shown that by increasing age of women, the performance in BSE and BCE has promoted. This findings has been in accordance with those reported by Avci (11) that the performance of BSC increased by ageing. In contrast Parsa et al. (12) has reported that the knowledge of BSE among Malaysian has not associated with age. The mean age of our participant was $31.5 \pm 9.4$ years and roughly a quarter of our sample aged over40 years. Thus our participants were relatively younger. This was likely due to refer the younger married women for receiving prenatal cares or any cares for their child or family planning.

In our finding $45.4 \%$ of participants were aware of aging as a risk factor for breast cancer. This knowledge probably has helped the women to increase their knowledge regarding breast cancer risk factors by aging. Thus, their health motivation has helped to perform BSE as primary screening method. While a study among African-American women has not reported aging as determinant in performance of breast cancer screening (13). This inconsistency with our findings perhaps was due to lower educational level of older women in the later study.

Our findings have emphasized the role of education at university level as a significant determinant of BSE. This finding was consistent with other studies in Iranian women (14-16) and other Asian countries as well (12). In addition we have found that the knowledge of risk factors has significantly associated with educational level. Additionally, higher educational level has significantly associated with women's belief toward breast cancer as serious disease and their feelings and their perceived susceptibility, and thus it has influenced their health motiva- tion. Therefore, elevating the level of knowledge through several path ways has resulted in better performance of women in BSE or BCE.

Regarding to the awareness of breast cancer risk factors roughly half of our study samples had poor knowledge and only $14.8 \%$ of subjects had high level of knowledge, then we have found a significant relation between knowledge of risk factors and symptom, with BSE and BCE. These results also were in accordance with those reported among Kuwaiti (17), Chinese (18) and Turkish (19) women that all have reported the low level of knowledge as a determinant of delay in diagnosis and lack of participation in breast cancer screen program. In our study, $80 \%$ women have not participated breast screening educational program and also $37.2 \%$ have not shown any information regarding BSE while this figure was $49.9 \%$ and $73.8 \%$ in Chinese (18) and Turkish (19) women respectively, which has been relatively higher than ours. Despite, our results have emphasized the extension of educational program in order to increase the awareness for BSE and BCE in health care system.

The positive belief regarding to breast cancer among women had crucial role on screening. In our findings the majority of participants have believed low perceived of susceptibility and less seriousness as negative attitudes. While we have not found association of susceptibility and seriousness with BSE but high perceived of benefit, confidence and high health motivation have significantly associated with BSE. The cultural belief and barriers might be differing in different cultures and the contradiction of findings was apparent in different reports $(12,13)$.

Regarding regular performance of BSC, in our findings 10.1\%of subjects have performed BSE once in a month. In contrast, this percentage was 31\% in African American (20), 19\% in Malaysian (11) and 17\% in Turkish women (19). As we have addressed already, the differences might be attributed to culture, knowledge and beliefs in different societies.

The practice of BCE by physician or nurses was the second step in breast screening program (21). American 
cancer society has recommended BCE for women aged 20 years once every two years and at age 40 annually. In our studies $74.8 \%$ of participants have never tried BCE and only $9.8 \%$ have examined with a chief complaint of pain. The performance of BCE has increased with awareness of risk factors and age at median (30 - 50 years). A similar finding has reported in Iranian women in other studies $(7,14,22,23)$ and other Asian countries as well (12). It seems cultural barriers, poor knowledge and negative beliefs can explain the low practice of women in BCE.

Mammography as a standard procedure of screening has performed annually for women at aged 40 or older in general population in western countries and it has not recommended for women age less than 40 . In our study, on overall, $39.6 \%$ of women had no information on mammography. While in the study by Alharbi et al. (17) in Kuwaiti women this percentage was almost double. We have found $28.5 \%$ of women aged $>40$ years have applied mammography at least once. A similar finding has reported among Turkish women (19) while the practice rate was much lower in the reports among Malaysian and Chinese women $(12,18)$.

In conclusion, the results have shown the low performance of women in BSE and BCE. Aging, higher educational level, knowledge and attitude toward benefit and health motivation have associated with practice of BCS. An extensive educational program has recommended for BCS, particularly, among younger and low educated women.

\section{Acknowledgements}

We have acknowledged the Deputy of Research of Babol University of Medical Sciences for their supporting of this study.

\section{Authors' Contributions}

Dr Karimollah Hajian-Tilaki and Dr Sahar Auladi have designed and written the article. Dr Auladi has collected the data and Dr Hajian-Tilaki has analyzed the data. All authors have contributed to writing this article. All read and approved the final manuscript.

\section{Conflict of Interest}

There was no conflict of interest to be declared.

\section{Financial Disclosure}

The authors declared that they have no competing interest.

\section{References}

1. Jemal A, Center MM, DeSantis C, Ward EM. Global patterns of cancer incidence and mortality rates and trends. Cancer Epidemiol Biomarkers Prev. 2010;19(8):1893-907.

2. Harirchi I, Karbakhsh M, Kashefi A, Momtahen AJ. Breast cancer in Iran: results of a multi-center study. Asian Pac J Cancer Prev. 2004;5(1):24-7.
3. Hajian Tilaki K, Firozjaii AR, Kia MT. Pattern of age distribution of different cancers in Babol, [in Persian]. J Res Med. 2001;27:239-45.

4. Hajian-Tilaki KO, Kaveh-Ahangar T. Reproductive factors associated with breast cancer risk in northern Iran. Med Oncol. 2011;28(2):441-6.

5. Nelson HD, Tyne K, Naik A, Bougatsos C, Chan BK, Humphrey L, et al. Screening for breast cancer: an update for the U.S. Preventive Services Task Force. Ann Intern Med. 2009;151(10):727-37.

6. Nestom L. How effective is screening for breast cancer. Br Med J . 2000;16:647-9.

7. Haji - Mahmoodi M, Montazeri A, Jarvandi S, Ebrahimi M, Haghighat S, Harirchi I. Breast Self - Examination: Knowledge, Attitudes, and Practices Among Female Health Care Workers in Tehran, Iran. Breast J. 2002;8(4):222-5.

8. Secginli S, Nahcivan NO. Reliability and validity of the breast cancer screening belief scale among Turkish women. Cancer Nurs. 2004;27(4):287-94.

9. Parsa P, Kandiah M, Mohd Nasir MT, Hejar AR, Nor Afiah MZ. Reliability and validity of Champion's Health Belief Model Scale for breast cancer screening among Malaysian women. Singapore Med J. 2008;49(11):897-903.

10. Dündar PE, Ozmen D, Ozturk B, Haspolat G, Akyıldız F, Coban S, et al. The knowledge and attitudes of breast self-examination and mammography in a group of women in a rural area in western Turkey. BMC cancer. 2006;6:43.

11. Avci IA. Factors associated with breast self-examination practices and beliefs in female workers at a Muslim community. Eur J Oncol Nurs. 2008;12(2):127-33.

12. Parsa P, Kandiah M, Mohd Zulkefli NA, Rahman HA. Knowl edge and behavior regarding breast cancer screening among female teachers in Selangor, Malaysia. Asian Pac J Cancer Prev. 2008;9(2):221-7.

13. Gullatte MM, Phillips JM, Gibson LM. Factors associated with delays in screening of self-detected breast changes in AfricanAmerican women. J Natl Black Nurses Assoc. 2006;17(1):45-50.

14. Yavari P, Pourhoseingholi MA. Socioeconomic factors association with knowledge and practice of breast self-examination among Iranian women. Asian Pac J Cancer Prev. 2007;8(4):618-22.

15. Banaian S, Kazemian A, Khaiari S. Knowledge, attitude and practice of women attending to Health Therapeutic center of Brojen Iran about breast cancer screening methods and it determinants (2003), [in Persian]. J Kord city Uni Med Sci. 2004;7(4):28-34.

16. Talaiezadeh A, Sarmast Shoshtari M. H., Ansari N. Knowledge of woman aged above 18 years attending to health therapeutic center Ahvaz/Iran about breast self-examination, [in Persian]. Jondishapour Med J . 208;7(4):504-12.

17. Alharbi NA, Alshammari MS, Almutairi BM, Makboul G, El-Shazly MK. Knowledge, awareness, and practices concerning breast cancer among Kuwaiti female school teachers. Alexandria J Med. 2012;48(1):75-82.

18. Kim JI, Oh KO, Li CY, Min HS, Chang ES, Song R. Breast cancer screening practice and health-promoting behavior among chinese women. Asian Nurs Res (Korean Soc Nurs Sci). 2011;5(3):157-63.

19. Secginli S, Nahcivan NO. Factors associated with breast cancer screening behaviours in a sample of Turkish women: a questionnaire survey. Int J Nurs Stud. 2006;43(2):161-71.

20. Hajian-Tilaki K, Auladi S. Health belief model and practice of breast self-examination and breast cancer screening in Iranian women. Breast Cancer. 2014;21(4):429-34.

21. Sadler GR, Ko CM, Cohn JA, White M, Weldon RN, Wu P. Breast cancer knowledge, attitudes, and screening behaviors among African American women: the Black cosmetologists promoting health program. BMC Public Health. 2007;7:57.

22. Salimi-pormehr S, Kariman N, Sheykhan Z, Alavi-majd H. Investigation of breast cancer screening tests performance and affecting factors in women referred to Ardebil's health and medical centers, [in persian]. Ardebil Med J . 2009;10(14):310-8.

23. Ghodazandeh G, Khani H, Khalilian AR, Atarod Z. Knowledge and practice of women aged above 15 years in Sari about breast cancer in 2004. JMazandaran Uni Med Sci. 2006;16(52):64-7. 